\title{
Design and Aesthetics in Nanotechnology
}

\section{Sacha Loeve}

Institut de Recherches Philosophiques de Lyon (IRPhiL)

Université Jean Moulin Lyon 3 France

sacha.loeve@univ-lyon3.fr

\begin{abstract}
What is the status of "design" in nanotechnology? On the one hand, scientists doing nanotechnology refer to their activity as "design." On the other, the intervention of design researchers and practitioners remains confined to "the future" (i.e. societal applications and uses of nanotechnology). How are we to understand such a division of labour? To be sure it is not specific to nanotechnology but concerns the status of design in contemporary technoscience at large. However, the problem is more acute in the case of this "invisible" technology. Nanotechnology is supposed to be cut off from all sensible experience whereas design traditionally focuses on the shaping of the user's experience. After articulating the diagnosis and its implications, I question the status of a third player: "nano-art." I then draw on some resources of French philosophy of technology and aesthetics to prompt a new alliance between "techno-logy" (the study of technics) and aesthetics (the study of sensation) resulting in a re-conceptualization of design as "techno-aesthetics." The chapter closes by highlighting the political significance of such techno-aesthetic design for nanotechnology and beyond, for our everyday live amidst technoscientific objects.
\end{abstract}

Keywords: aesthetics, aesthetical apparatus, techno-aesthetics, technoscience, design, images, nano-art, nanotechnology, noumenal technology

\section{Why design is everywhere and nowhere in contemporary technoscience}

"Design" is a keyword in contemporary technoscience. It pervades the mundane parlance of synthetic biology and nanotechnology. While synthetic biology focuses on "life by design," (Bensaude Vincent 2015) the so-called "nanoworld" is depicted as a "world by design." Its atomic landscapes are like an invitation to enter a new world that humans would have thoroughly designed (Hanson 2012). Nano-objects and nanostructured materials are processed and studied as outcomes of a design work. Sometimes, genomes and materials themselves are called "designers" (Annaluru et al. 2014; Chong and Garboczi 2002; Shwartz 2015). Even nature is depicted as a "nanodesigner" that "invented" the molecular machinery of life more than three billions years ago (Jones 2004)—hence the popular "re-designing" phrase.

Such phrases rely on the polysemy of the word "design," which refers either to the plan, form or blueprint dictating the realization of an artifact, or to the immanent and distributed organization of a form-making process (Dilnot 1984; Buchanan 1992). Both meanings resonate with the ambivalence of synthetic biologists and nanotechnologists which oscillate between an overemphasis on the activity of human intelligence shaping a passive matter (i.e. the hylemorphic 
attitude criticized by Simondon (2005)) and the capture of the spontaneous activity and information embedded in molecules and genomes ${ }^{1}$.

Interestingly, the co-occurrences of "nanotechnology" or "synthetic biology" with "design" on Google outnumber those with "understanding," "knowledge," or "explanation," as well as those with "fabrication," "production," or "manufacturing." As "design" refers both to an intellectual activity and to a practical one, it seems well suited to substitute for notions belonging either to "science" or to "technology," and even more relevant for "technoscience" as a mode of research subverting the dualisms of representation/action, structure/operation, process/product, nature/artifice, pure/ applied, praxis/poiesis, etc. (Bensaude Vincent et al. 2017). What is more, the word "design" does not suffer from the bad reputation of the later term, especially in France (Bensaude Vincent and Loeve, Chap. 11, this volume).

Enough for the word design in nanotechnology. But what about design as practice? On the one hand, nanoscale scientists do "research by design" in that instead of limiting their questions to a pre-existing range of available materials, they are free to raise questions that can only be addressed by synthesizing the desired research object endowed with tailored-made properties for performing specific behaviors and functions (Marcovitch and Shinn 2014). They equate design with "technological conception" just like engineers do, although unlike engineers, technoscientists generally limit their endeavors to establishing proofs of concept, i.e. to the demonstration of the feasibility of a product or process, unconcerned with the practical conditions of its actual completion. They (or their nanodevices) perform electronic, optical, magnetic, chemical or biological "design" in this sense. As to the handful of books more explicitly devoted to "nanodesign" (Rieth 2003; Ashby et al. 2009; Schommers 2013), they generally start with the basic laws of physics at the nanoscale and then address principles and rules of engineering; only toward the end do they touch upon the "broader" environmental and societal issues. They address "nanodesign" as a matter of applied science.

On the other hand, few researchers and practitioners in design intervene in nanotechnologies, or only at the margins. For instance, designers of the Laboratoire Innovation et Technologies centrées UtilisateurS (LituS) based in the nanotechnology center Minatec in Grenoble, is dedicated to the exploration of user's experiences of nano-embarking prototypes with a view to understand their conditions of adoption, appropriation and desirability (Delhome 2011). Design researchers also work at the IDEAs Lab ${ }^{\circledR}$ to co-construct "anticipated use scenarios" of nanotech-based products with social scientists and "potential users" focus groups. The reports of the design team are sent back to the so-called "technologists," who are then supposed to better adapt the technical functionalities to users. A strict division of labor is observed: "technologists" are the engineers in charge of translating the "technological bricks" that come out of the research lab into usable functionalities, while designers are in charge of translating these functionalities into potential social uses. Their main goal is to facilitate the appropriation of nanotechnology.

This approach to nanotechnology design is somewhat contradictory: it is supposed to be user-centric although stricto sensu there is no "user" of nanotechnology. Nanocomponents are always packaged into larger modules or systems

\footnotetext{
${ }^{1}$ In other terms, they hesitate between "fabrication" and "piloting" (Larrère and Larrère, Chap. 12, this volume).
} 
so that users have no direct relationships with the nanoscale operations embedded in the final product. Users interact with computers, networks, screens, glasses, fridges, tires, clothes, medicines, cosmetics, food, etc., that embark or embed nanomaterials and systems, and never with nanotechnology per se. In this case design in nanotechnology is therefore not about designing the technology but about adapting already constituted "technological bricks" to (potential) users.

Designers in nanotechnology endorse and reinforce the divide between two understandings of design: the concept familiar in engineering (technological conception) and that of the designer (the framing of user-experience). The former is dealt with as an object-centred problem of applied science and engineering, the later as a human-centred matter of meaning, and the question is settled. In this perspective, the practice and meaning of design is trapped in the same dualisms that the technoscience is challenging (object/subject, science/society, technology/culture, etc.).

Yet another trend of design aims precisely at questioning these divides. Following "critical design," (Dunne 2006) "debate-provoking design" set up situations and performances for stirring discussion and questioning our attitudes, ethical values and judgements towards nanotech.

For instance, in the "Cloud Project" (Fig. 1), artists Zoe Papadopoulou and Cathrine Kramer park their ice cream van in the streets, inviting people to taste ice cream frozen with liquid nitrogen. The freezing occurs so quickly as to produce nano-sized ice crystals and a very smooth ice-cream, jokingly referred to as a Grey Goo Sunday. The stated goal of The Cloud Project is to make clouds snow ice cream. Ice creams are given in exchange for a conversation about nanotechnology and geo-engineering. True or not, this street event is meant to awaken people's imagination and to invite them to discuss and debate nanotechnology, geoengineering and climate change.

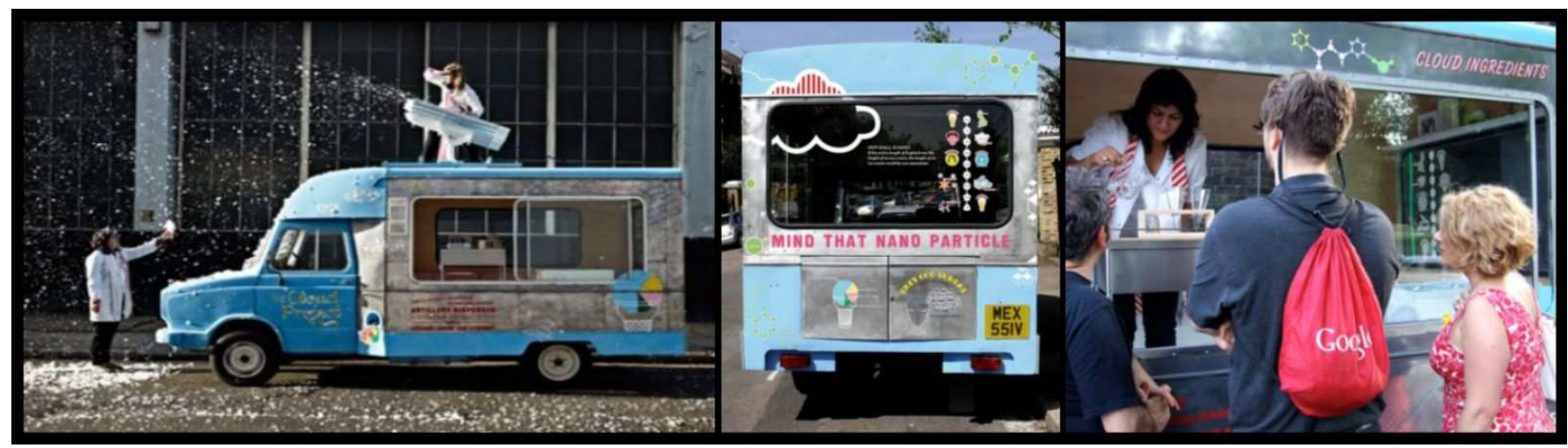

Figure 1. Cloud Project, Zoe Papadopoulou, Cat Cramer. (Picture assembled by the author; courtesy of Z. Papadopoulou and C. Kramer)

Another example is the itinerant NANO Supermarket related to Dutch designer Koert van Mensvoort's project Next Nature (Fig. 2). ${ }^{2}$ People are encouraged to discuss speculative uses of nanotechnology such as NanoLift, a "physical photoshop" enabled by magnetic nanoparticles injected into the skin or a wine containing on-demand programmable nanocapsules to alter taste, smell and color. One may also speak of "speculative design." (Auger 2013)

\footnotetext{
${ }^{2}$ http://www.nanosupermarket.org/products
} 


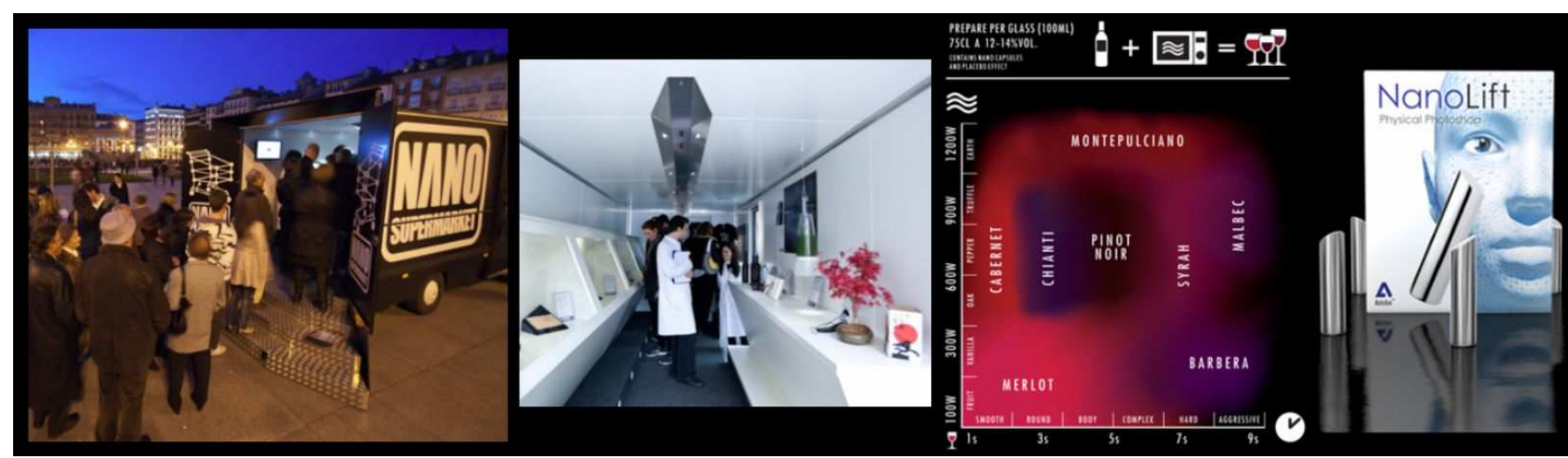

Figure 2. NANO Supermarket, Koert van Mensvoort. (Picture assembled by the author; Courtesy of K. van Mensvoort)

These projects are enjoyable, fun, and sometimes provide real opportunities for exchanging views and confronting values. But they are also revealing of a paradoxical situation: a chasm between technical objects without uses and uses without technical objects.

\section{The Technoscientific Chasm}

Laboratory nano-objects like molecular machines, electronic nanodevices or sensors/actuators are genuine technical objects in the sense of Simondon: they perform a definite "technical individuality." (Loeve 2010) ${ }^{3}$ Yet most of them are designed regardless of any practical usage. Some have applications, however "application" differs from use. Use contains an unavoidable and unpredictable dimension of social reconstruction and sometimes hijacking of the object's functionality. The only genuinely technical uses of nano-objects are those of scientists in the lab. In most nanotech-embarking applications, the "nano" character is made to go unnoticed and unmodified by the final user. It is made to function, not to be used.

Conversely, proposals of critical and speculative design are genuine uses. They are not reducible to "science communication" as they generate meaning by exploring ambiguities, dilemmas, unknowns and potential alternatives to "conventional" designs (i.e., to applications). However, designers make this possible only by designing speculative objects lacking technical individuation.

Hence a paradoxical situation: on the one hand, scientists design actual technical objects without uses (and only in some cases with applications); on the other, designers elicit actual uses without technical objects (or only with speculative ones). "Object" and "use" remain mutually exclusive. Design in nanotechnology is thus cleaved between objects with speculative uses (futuristic scenarios and promises) and uses with speculative objects (fictional proposals and projects). While the work of designers becomes almost undistinguishable from that of speculative ethicists (Nordmann 2007), scientists tend to monopolize the design of the nanoworld by framing it as an applied-science kind of engineering whose

\footnotetext{
${ }^{3}$ A technical individual according to Simondon (1958) is an object that has gone through a process of "concretization" by which the object unifies itself by integrating into its functioning scheme some specific features of its environment (here the nanoscale properties of their physico-chemical environment). The technical individual is no more an "abstract" object (the mere materialization of a theory adapted to an external environment) but a concrete object in an "associated milieu."
} 
social dimensions are external to technology, limited to the context of application. This chasm has important sociocultural repercussions: it maintains the technical part of nanotech in some kind of parallel world - the "nanoworld"-out of reach for social users.

By contrast, other fields of design establish a real connection with technology. Ecodesign focuses as much on humans' awareness of their interactions with the environment as on the circulation, appropriation, production and conception of the technologies that condition this awareness. Information design focuses as much on users' experiences as on the interfaces that shape users' interactions with computational processes, devices and networks (Vial, Chap. 23, this volume). When it comes to nanotechnology, there are no "nanodesigners" in charge of designing our interactions with the nanoworld. The design of the nanoworld is handled by scientists, while designers work only on the symbolic, metaphoric and societal dimensions of the "technology-in-the-future." As a result of this division of labor users have poor interactions with the present technology, either through applications where the nano-dimenson is withdrawn from use, or through speculations where the nano-dimension is projected into "the future."

Of course engineers and designers are two distinct professional groups and their separation is the heritage of a long history. But whatever its socio-cultural reasons this separation is possible because of the existence of an irreducible margin of indetermination between the functioning and the uses of a technical object. As Simondon emphasized (1958), the same functioning schemes can give rise to different uses while the same use can be obtained from different functionings. ${ }^{4}$ And just as Simondon insisted that technicity ${ }^{5}$ is irreducible to use, most designers do not want to reduce the meaning of use to the bare actualization of functioning (let aside pure functionalism as a limit-case ${ }^{6}$ ). Yet the existence of a gap does not prevent bridges to be established, quite the contrary: the gap between functioning and use affords the very space of problems and possibilities in which design operates. ${ }^{7}$ In other terms, to design is to work with and within this zone of mismatch and indeterminacy between functioning and use. ${ }^{8}$ The practice of design is such that

\footnotetext{
${ }^{4}$ To Simondon, use-categories refer less to the objects' intrinsic functioning than to the practical functioning of humans. From the point of view of functioning, he notes, there is more analogy between the elastic motor and a bow or arbalest than between the same motor and a steam motor, although from the point of view of use, the latter two are put into the same "motor" category (Simondon 1958: 19; Loeve 2016).

${ }^{5}$ I.e. the degree and modality of concretization.

${ }^{6}$ Functionalist designers or architects like Bruno Munari, Ludwig Mies van der Rohe or Le Corbusier, were allegedly observing the principle "form follows function." In practice, they were rather opposing an aesthetics of functioning to the aesthetical masking of technicity (Antonello 2009).

${ }^{7}$ For Simondon it was precisely the aim of "industrial aesthetics" - the 1950-1960s French phrase for 'design' (Beaubois and Petit, Chap. 21, this volume) - to mediate between technicity and use in a particular culture or, as he had it, to "organize technophany," the aesthetical manifestation of technicity (Simondon 1960-1961: 39). For instance, the casing enclosing the mechanics of a clock watch is not only an embellishment. It is a membrane that both separates and links the delicate movement pieces and the social use of time. It is simultaneously a symbolic system and a protective membrane-the condition to develop, inside, the mechanical functions.
}

${ }^{8}$ To venture a "physics-for-dummies" metaphor, design operates neither like an insulator (isolationist discourse: science on the one hand, society on the other, and a forbidden gap between the two) nor like a conductor, with technical functioning dictating social use (deterministic or applicationist discourse: 
it constantly redefines use-value instead of regarding it as a given, be it in the functioning of technical objects (limit-case of strict functionalism) or in socioeconomic behaviors (limit-case of pure marketing).

Therefore the question remains to understand why designers do not engage in establishing bridges between the functioning and the use of nanotechnology. As I will argue, the answer lies into a specific "distribution of the sensible." (Rancière 2004) To understand this, let us first examine the contribution of a third player, who blurs the division of labor between nanotech and design: nano-art.

\section{Nano-tech and Nano-art}

The practices of nano-art have played a key role in nanotechnology's rise to prominence since The Beginning (Fig. 3), an $\mathrm{STM}^{9}$ image spelling the letters I.B.M. with 35 xenon atoms on nickel surface (Eigler 1990). Scientists refer to it as "art" because it signs the intentional imprint of Man in a hitherto untouched medium. The Beginning became soon a visually compelling evidence of the human ability to manipulate the world atom-by-atom (Schummer 2006), a powerful flagship for promoting large-scale implementation of nanotech funding initiatives (Toumey 2010), an evangelistic tool for the radical proponents of a "molecular manufacture," a worshiped icon for a growing number of scientists converting their research projects into "nano" ones.

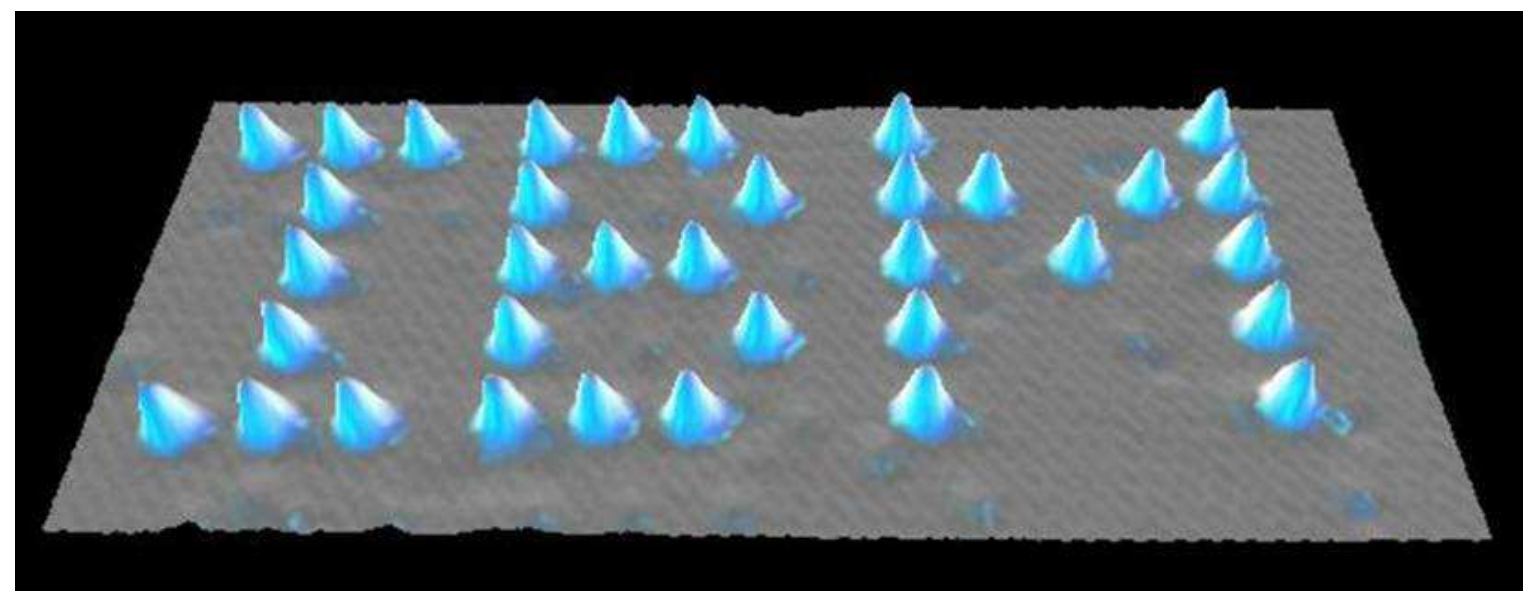

Figure 3. The Beginning. (Don Eigler, (C IBM)

This inaugural feat revealed the STM's potential beyond that of an observational instrument for "reading" atomic structure: as a tool for manipulating and "writing" with atoms. Since then, scanning probe microscopy manufacturers like Veeco Instruments or Omicron have encouraged (and sponsored) nano-art for promoting their instruments and exhibiting the unprecedented mastery they provide. With the rapid dissemination of scanning probe microscopy a plethora of practices

science-hence-application-hence-use). Design operates like semiconductor: it modulates gently the zone of relative mismatch between technicity and use to cross the forbidden gap and constantly redraw its borders.

${ }^{9}$ Scanning tunneling microscope. The image has been dubbed "The Beginning" retrospectively for its 1994 3D colour-publication on the IBM's STM Image Gallery website.

${ }^{10}$ Such as Eric K. Drexler: "Five years ago, audiences questioned whether individual atoms could be placed in precise patterns; today, I can answer that question not just with calculations, but with a slide showing the letters 'IBM' spelled using 35 xenon atoms." (Drexler 1992: 1) 
consisting in tagging, drawing or signing matter at the nanoscale have been displayed (Fig. 4). These images mean both "I've been here!" and "I've done that!" They stage the exploration of a world of our own design, a plastic world turned synthetic, with material building-blocks as easily actionable as bits of information.

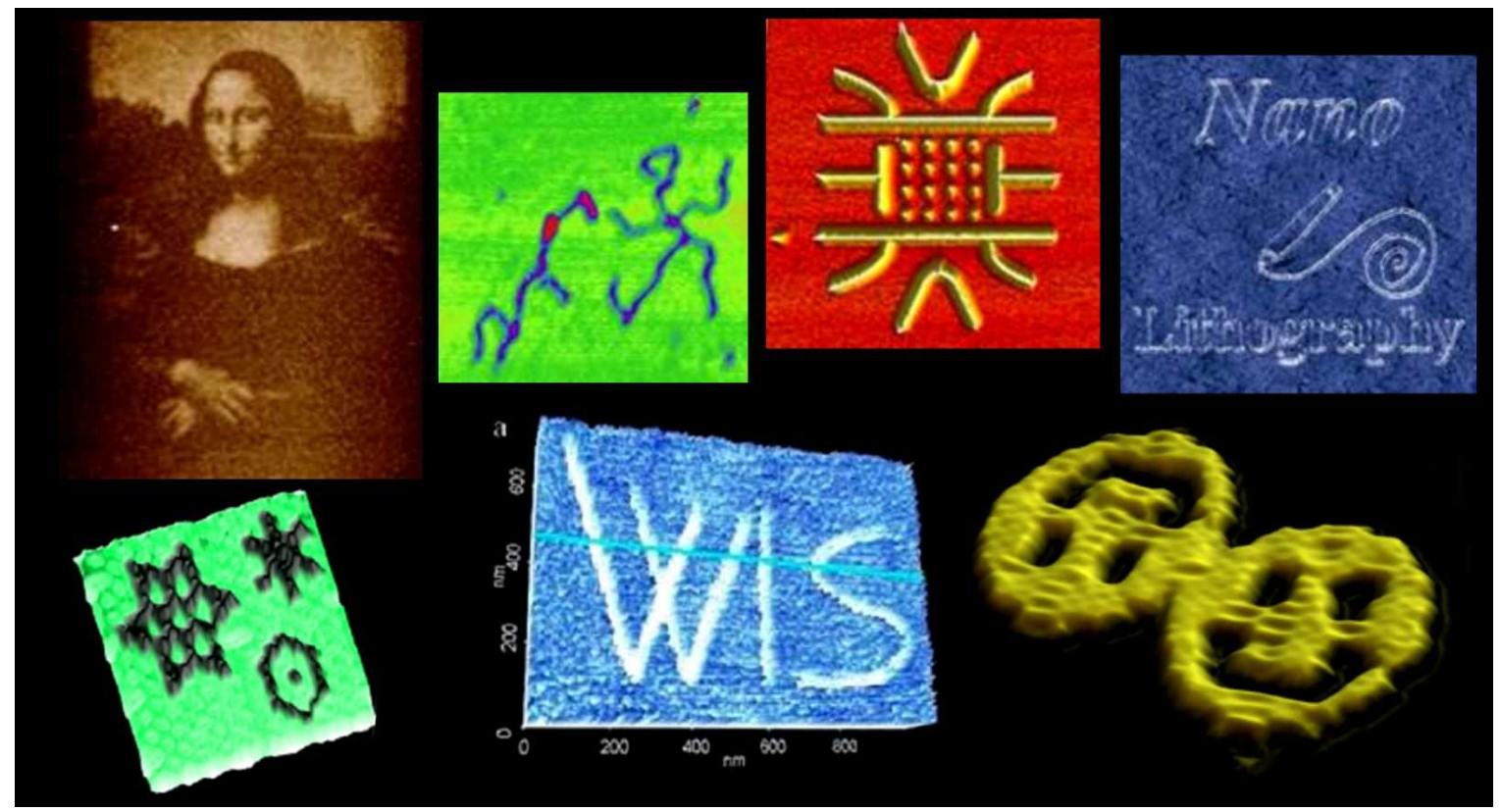

Figure 4. Plastic world. (Picture processed by the author)

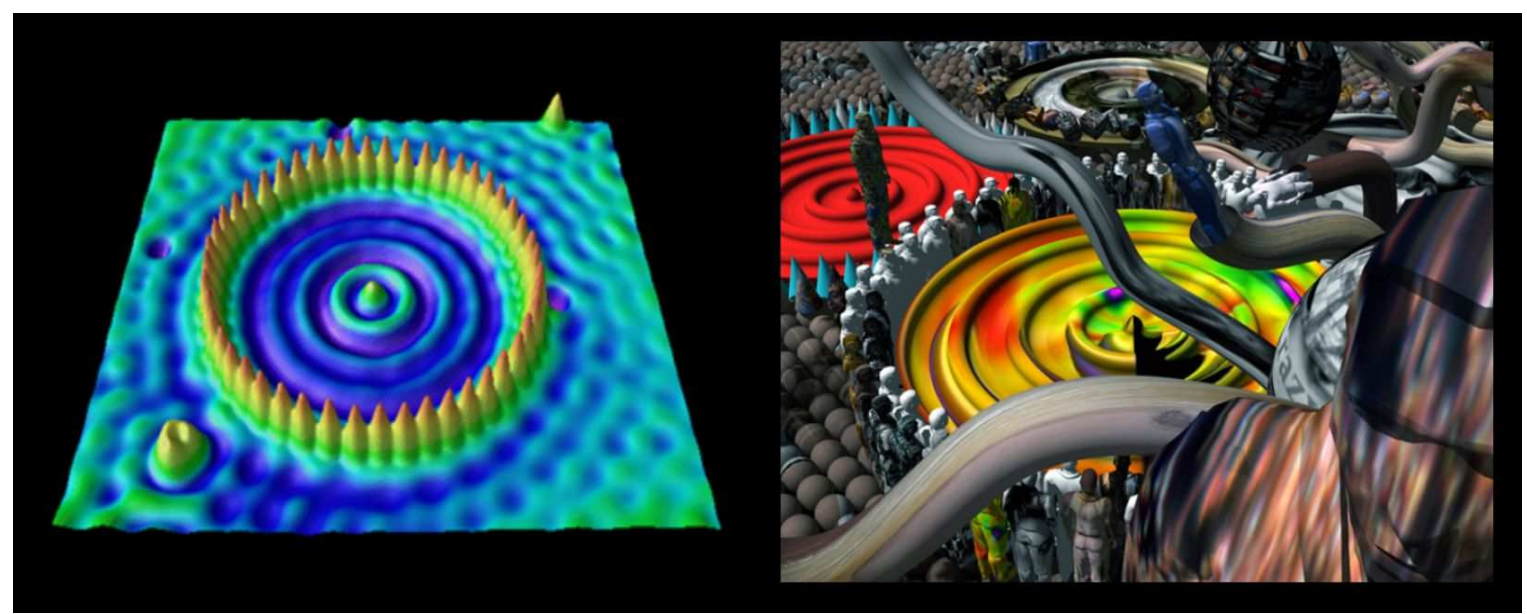

Figure 5. Left: Quantum corral by Don Eigler (@ IBM). Right: Eigler's eyes 2 by Chris Robinson. (Courtesy of Chris Robinson)

These productions were powerful marketing devices which contributed to the hype about nanotechnology and the economy of promises conditioning their funding (Audétat et al. 2015). The political function of nano-images as lures for the future is what suggests a work by visual artist Chris Robinson, entitled Eigler's Eyes 2. In this piece, Robinson hijacked one of Don Eigler's achievements, the "quantum corral," 11 and replaced the ring of atoms by a circle of human figures (Fig. 5) as if it were our collective gaze on the nanoworld that created the phenomenon of interest.

\footnotetext{
${ }^{11}$ Where one can visualise circular standing waves of electron density, a "quantum-classical" phenomenon.
} 
The piece thus suggests a "nano-society of spectacle" where one essentially consumes images, a "glitter science" that seeks mostly to catch attention.

The image of carbon nanotubes transistors aligned between gold electrodes used for the cover of a 2001 issue of the journal Science (Fig. 6) is not a work of nano-art but a so-called "artist's depiction," an image conveying a vision of what could be done in the best of possible (nano)worlds. Since the atomic structure co-exist with the representation of the macroscopic material this image had defrayed the chronicle in nano cenacles all around the world for it is a scientific nonsense. Criticisms were pointing to the trend of the most prestigious scientific journals to favour the most "sexy" images over more rigorous ones (Ottino 2003).

Another artist's depiction worth mentioning is the cover of the brochure Nanotechnology: Shaping the World Atom by Atom (Roco et al. 1999). This brochure $^{12}$ aimed at convincing US senators to vote the colossal budget planned for the US National Nanotechnology Initiative. The cover (Fig. 7) displays a STM image of silicon surfacescape set against a "cosmic" background. Using central perspective, the forefront invites the viewer to "enter into a new world" decentred from the earthling referential. The Earth is seen from afar as if the viewer was landing on the bumpy surface. The background evokes the extension of the human enterprise beyond all frontiers by recycling the old heroic imagery of the conquest of space. The picture mixes the infinitely small and the infinitely vast,

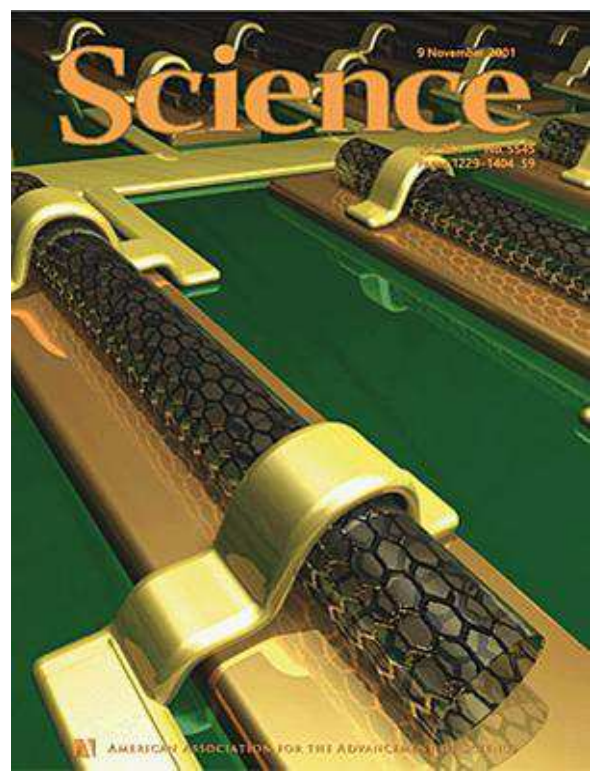

Fiqure 6. Aberrant science

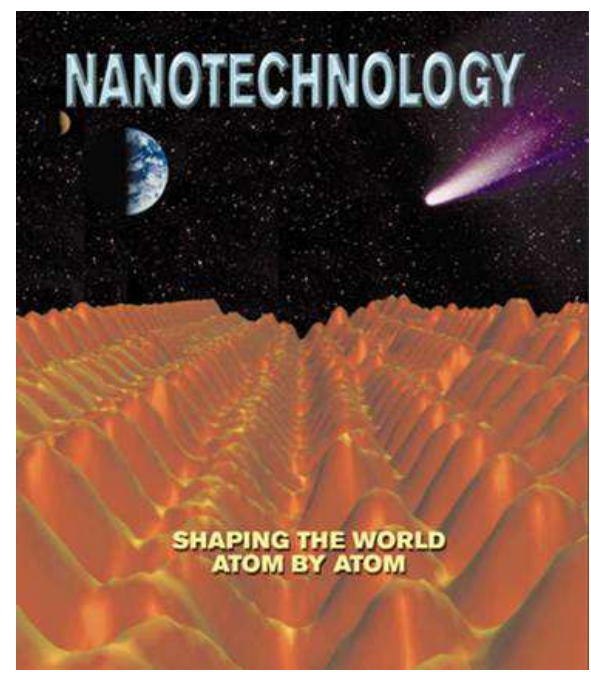

Figure 7. Cover of the US Government brochure Shaping the world atom by atom the outer space of the universe and the inner space of matter; it stages the nanoworld as a place waiting to be colonized.

Nano-art competitions are instrumentalized by research agencies to improve their public image. For instance, the nano-art imagery contest organized on a monthly basis by the Smalley Institute at Rice University and the company nanoTox ${ }^{\circledR}$ awards winning entries "based on a combinations of visual beauty and technical marvel." It is explicitly stated that "The goals of the contest are to have Fun and to promote the public's acceptance of and interest in nanotechnology: most

\footnotetext{
${ }^{12}$ Co-edited by the President's Committee of Advisors on Science and Technology (PCAST), the National Science and Technology Council (NSTC) and the Interagency Working Group on Nanoscience, Engineering and Technology (IWGN).
} 
people who are new to the topic really start to 'get it' when they see compelling pictures." ${ }^{13}$ Nano-art also simply allows attracting kids and inspiring vocations. For instance, IBM researchers at Almaden have made a movie in stop motion with carbon monoxide molecules. A small boy named Atom falls in love with a molecule and plays with her (Fig. 8). The message is clear: nanotechnology is full of love and fun (Milburn 2011). One scientist comments: "If I can do this by making a movie, and I could get a thousands kids to join science rather than going to law school, I would be super happy."14

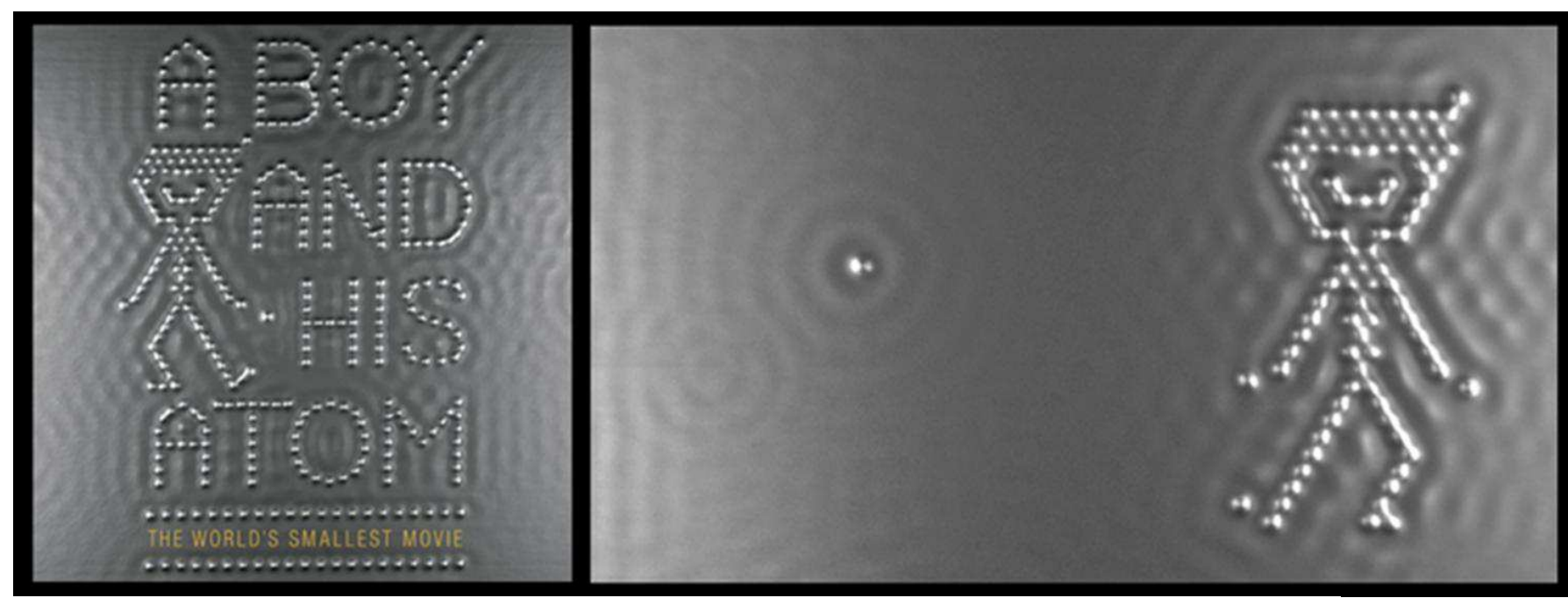

Figure 8. Playful nanotechnology. (@ IBM, source: https://www.youtube.com/watch?v=0SCX78-8-q0, image capture by the author)

Many of these images have been abundantly commented (Slaattelid and Wickson 2011). In nanotech as elsewhere, science-art projects are in vogue because they are regarded as means to overcome the unfortunate divide between the "two cultures." (Snow 1959) Showcasing nanotechnology as "art" provides a cultural alibi and a tool of social acceptability. ${ }^{15}$ Symmetrically artists may use nanotech to broaden their repertoire of impressive "effects" for performing technical prowess.

\section{Radical-Otherness-Hence-Appropriation}

This detour by (the mainstream of) nano-art uncovers the shared assumption that rules the division of labor between nanotech and design.

The slogan "making the invisible visible," often used for summarizing the purpose of nano-art (Raimondi 2007; Ruivenkamp and Rip 2010; Baccile and Balzerani 2013), presupposes that the nanoworld is in itself invisible, uncanny, strange, occult, counter-intuitive, etc. It is supposed to be a world apart, withdrawn in itself, radically different, occult, defying common sense and eluding any sensible intuition the kind we use in our everyday, phenomenal world. Especially because of its "quantum" nature, the nanoscale would be attainable only by an abstract science and accessible only to the initiated. As Alfred Nordmann had it, nanotech is framed

\footnotetext{
${ }^{13}$ http://nanoart.blogs.rice.edu/

${ }^{14}$ Andreas Heinrich, https://www.youtube.com/watch?v=xA4QWwaweW A (4'20).

${ }^{15}$ This way of resorting to "art" to show technoscience "in culture" can also be regarded as an implicit admission of failure of scientific and technical culture (Lévy-Leblond 2010).
} 
as a "noumenal technology": a technology of the "things-in-themselves," (noumena $)^{16}$ that retreats from human access, perception, and control (Nordmann 2005). Thus nano-art, be it practiced by artists or by scientists, aims at the appropriation of the nanoworld: if the nanoworld is noumenal it has to be rendered phenomenal; if it is invisible it has to be rendered visible; if it is uncanny it has to be rendered familiar; if it is scary it has to be rendered fun, etc. It aims at making the nanoscale culturally appropriable, at making it fit in our daily lives.

Yet designers seem to start from the same pre-assumption as they seek to translate the "uncanny otherness" of the noumenal into the phenomenal. The role of nanodesign would be to build up mediations in order to turn these noumenally constituted technologies into sensible, appropriable, meaningful, and debatable things (Delhome 2011).

I refer to such implicit preconceptions as radical-otherness-henceappropriation. Its rhetoric is reminiscent of that of twentieth-century physics popularization, showcasing relativity and quantum physics as remote universes inaccessible to common sense, and scientists as priests accessing the hidden reality of things. It corresponds to a public image of science based on the pre-assumption of a gap that should be bridged by popularizers to educate the public. ${ }^{17}$

In the case of a technoscience like nanotechnology, this rhetoric is misguided. The very idea of an "epistemic rupture" between science and lay knowledge, emphasized particularly by Gaston Bachelard (1938), does stand for technoscientific objects. Nano-objects are not "theoretical entities" prone to provoke debates between realists and instrumentalists; they are conceived (and visualized) as mundane and actionable building blocks that afford functionality and performance (Bensaude Vincent et al. 2011). ${ }^{18}$

In brief, do we need nano-art for making the nanoworld visible and familiar when nanotechnology already does it? In taking up the rhetoric of the radical otherness of the nanoscale, the mainstream of nano-art condemns itself to practices that are mimetic to the technoscience instead of trying to make a difference. As to design, it finds itself stuck between nanotech, which monopolizes the design of the nanoworld, and nano-art, which tends to aestheticize it.

\section{The Nanotechnological Sensible}

An epistemic version of the "radical-otherness-hence-appropriation" argument is that "nanotechnology produces visible representations of the invisible." I would like to dispute this claim.

\footnotetext{
${ }^{16}$ Although qualifying atoms and molecules as noumena (vs. phenomena) is incorrect from a Kantian point of view (since they are objects of science we constitute them as phenomena in space and time and subject them to principles of causality, conservation, etc.), Nordmann uses this phrase to emphasize the disruption of the traditional sequence "representation hence technical agency."

${ }^{17}$ In doing so, science communication was maintaining and even enlarging the gap between lay commonsense and a sacralized science while lamenting about the public's "deficit of knowledge" (Bensaude Vincent 2001).

${ }^{18}$ To give only two examples taken from quantum physics, in the nanoworld Heisenberg's principle of indeterminacy is no longer a mysterious property as it becomes a tool for making quantum confinement to enhance the electronic behavior of nanoparticles. "Schrödinger's cat" is no longer a thought paradox when it is used as a working laboratory device consisting of two coupled ultracold atoms with one measuring the other (Raimond et al. 2001).
} 
First, it relies on a misunderstanding of the novelty of nanotech. Indeed, from inertia to electromagnetic waves to atoms and molecules to quarks and black holes, it is modern science, not (nano)technoscience, that has populated the human world with visible representations of entities and processes that unfold beyond the reach of our senses-but obviously not beyond our ability to represent them. If there is a novelty in nano compared to quantum physics (which does "smaller than nano") or to chemistry (which has been working at the nanoscale since ever), it is precisely the possibility of experiencing individual molecular objects through devices that enact the sensitivity of this supposedly "noumenal" nanoworld; It is the possibility of a molecular aesthesis. The relevant novelty of nanotech does not lay in the "Nth industrial revolution" so fervently promised but in the new technical milieu of experience it affords by the instauration of unprecedented sensitive relationships with and within materiality.

Second, nano-objects are neither invisible nor visible; they would rather be "avisible," though not "a-sensible." They are indifferent to the dichotomy of the visible and the invisible that haunts the history and epistemology of modern science. The a-visible things, forces and processes of the nanoscale can be visualized, but they can also be listened and touched (and maybe one day smelled and tasted). The nanotechnological sensible is not restricted to the visual domain. Touch seems to be the prevailing sensory modality. Touch presents all kinds of nuances in the nanoworld, from caress to strike, from tact to prehension. Scanning probe microscopes operate like blind persons using a cane or reading Braille. The STM deciphers the properties of a conductive material by probing its electronic surface cloud. The vibrating cantilever of the atomic force microscope (AFM) brushes past slightly the material to sketch the main lines of its surfacescape in non-contact mode; in intermittent contact mode, it gropes around and gives gentle touches to localize the disposition of objects; in contact mode, it scrapes the surface to detail or alter its corrugation. Nanobiophysicists use optical or magnetic tweezers to grab motile proteins and feel their forces in motion. Nanotribology studies textures and friction at the nanoscale. Molecules recognize and bind to each other by mutual contact and prehension, etc.

However, just like vision, touch does not suffice to define the intrinsic character of the nanotechnological sensible. Its defining character is its transmodality. Nanotechnological operations present many kinds of transductions between different sensory modalities: visualizing tact, listening a surfacescape, touching light, etc. Transmodality is not specific to nano (for instance we usually translate written symbols into sounds while reading or visualize sounds when writing music) but the reversal: nano-percepts are specifically transmodal, and monomodal only when translated for human access. A nano-object or process is not audible nor visible nor touchable nor audible but all this altogether: it should rather be said "transible."

Most important, nanotech-generated images are not representations. They belong to a different regime of imaging, which I have named elsewhere "imaginaction" (Loeve 2011) or "the regime of image-objects." (Loeve 2009) ${ }^{19}$ As Michel Foucault argued, representation is "the dissociation of the sign and

\footnotetext{
${ }^{19}$ As opposed to the regime of representation. These concepts were inspired by Bergson's theory of perception as a process occurring into things according to action and not into their representation (Bergson 1896), and by Simondon, for whom perception is only one phase in the life of images (Simondon 2008). For both these two philosophers, images are not limited to the visible and can exist outside, before and after perception (Loeve 2011, 2015).
} 
resemblance." (Foucault 1966: 70) Representing requires a deliberate estrangement from sensible likeness, the construction of a distance between "object" and "image." This distancing, expressed in the "re" of re-presentation, is both a key principle of the scientific ethos (critical spirit and organized skepticism with regard to sensible data) and a concrete operation implemented in scientific instruments and settings. For instance, electron microscopes and spectroscopy techniques inscribe the trace of a distant interaction between a carefully prepared sample and a radiation emitted by the apparatus and then transmitted and/or diffracted by the sample. That the curve, spectrum or diffraction pattern re-presents the invisible properties of the sample means that its features are in principle distinguishable from those of the technical apparatus displayed to produce them. Both the realist's claim that the picture does represent some of the real properties of the sample and the positivist's claims that "this is just a representation" can only occur in the regime of representation. Whether something can be said about the real or about its representation, in both cases the real stands in the distance of "aboutness," independently of the instrumentation allowing its objectification (Nordmann 2006).

Now, in scanning probe microscopy constructing a distant picture of naturerepresenting-is no longer the problem. This family of instruments emblematic of nanoscale research has also been dubbed "local probe" or "near-field" microscopy to emphasize its difference versus other and subsequently dubbed "far-field" microscopes (from optical to electron) and spectroscopy techniques. In far-field microscopy, imaging and interpreting images means constructing a distance. In near-field, imaging is done in proximal rather than in distal mode, and interpreting the image means accounting for the tightest interaction between the technical conditions of imaging and the operative behavior of the object. An STM image of an atom is no more a model or a distant trace of an interaction with the sample's atoms; it is the interactive contexture of an object in a particular milieu configured by particular imaging conditions. The experimental image is literally the surface of the object co-acting with the probe mechanism of the instrument. It is an imageobject, whereby the manipulation of the object and the production of an image are one and the same process. The functioning of the instrument and the features of the object are no more separable.

A scanning probe image is both object-oriented and experience-oriented (Bueno 2008): it harbors information on the object as well as on the experimental mode of accessing it. But it is not only human experience-oriented. It is also about what it is like to perceive a nano-object from the perspective of another nano-object. In a number of nanotech experiments, an electron, a photon, a spin, an atom, a molecule, a surface or a nanoparticle is not only investigated as a target of study but also as a vector or proxy for addressing another object. It is not only an object for a subject (the human knower) but also an object for other objects. The observed object can shift to observing system and serve as a detector, sensor, probe, tool or actuator interacting with another object at its own scale and in its own mode. Nanoobjects are not noumenal, they rather extend the phenomenal to the relations between objects.

Of course, modern science deals with relations between objects, but only from the foreign perspective of the subject constructing a distant representation of them (a causal model for instance), not from that of objects sensing other objects. Modern science deals with interobjectivity but not with the interobjective sensible. It produces "objectivations of" while nanotechnoscience generates "objectivations with," whereby interobjective relationships are not represented from afar but 
participated from within. Nanotech's image-objects and local probes provide humans with access to the ways objects access their environments. This process of participation to interobjective relationships does not imply dry and narrow realism. It involves many imaginings, narratives, and never goes without recourse to metaphor (Bogost 2012)-i.e., the act of experiencing something in the terms of another, for instance: how a copper surface looks like for a cobalt atom (Stroscio and Celotta 2004). Metaphors, here, are not only to be understood figuratively but sometimes literally, when they lead to a functioning analogy by which things actually work together-for instance, a molecular "machine." (Browne and Feringa 2006) $)^{20}$

To recap, nanotech does not make visible representations of the invisible; it rather create a trans-sensibility below representation and beyond the subject-object correlation. ${ }^{21}$ It is not a technology beyond the sensible, but a technology that redefines the sensible. The nanotechnological sensible extends to relations between objects that can be shared with human subjects, be they technically or imaginatively instrumented. It delineates a new techno-aesthetic milieu.

\section{Three Techno-aesthetic Experiments}

Here I comment three projects that go beyond instrumental relationships between art and technology and do not consider the nanoscale as "otherness" to be appropriated into everyday experience; they rather consider the nanotechnological sensible as a new experiential space to be explored and questioned while providing an intellectual and emotional grip on its technological constitution.

1 .

Paul Thomas addresses the relation between humans and objects from the perspective of touch at the nanoscale (Thomas 2009; Hawkins and Straughan 2014). His project MIDAS uses an AFM for probing the relationships between skin and gold. The AFM cantilever, coated with gold, scans a sample of human skin culture cells (Fig. 9). The experiment challenges three preconceptions regarding touch:

- Subjectivity: Relying on the metaphor of touch attached to the AFM, the artist revisits the contact between skin and gold the other way round: it is gold that explores skin and generates data on its topography. His installation displays different possible renderings of those data in our macroscale sensory modalities: Touch, with a haptic interface, sonic transductions of the AFM data, and large-format visual projections that the visitor can modify through haptic interfaces. Both sensibilities, machinic and human, are made not identical but analogue, the one serving to understand the other and

\footnotetext{
${ }^{20}$ Although I maintain Simondon's definition of the metaphor as a "relation of identity" based on likeness versus analogy as an "identity of relation" based on operations (Simondon 2005: 108), in my perspective, the regime of imaginaction displays a continuous spectrum between the two.

${ }^{21}$ Following Quentin Meillassoux (2010) the proponents of "speculative realism" (Graham Harman, Levi Bryant, Ian Grant, Ray brassier) have tackled what they dub the "philosophies of access": philosophies that, after Kant, phenomenology and the linguistic turn, have renounced to state anything about the real in favor of a discourse on human access to reality. Speculative realists repeatedly argue that these philosophies commit the fault of letting the object-object relationships unthought at the benefit of subject-object or subject-subject correlations (Harman 2011). Without going too deep into this debate, let me just stress that it is possible to think human modes of access that borrow objects' modes of access to other objects. Thinking this kind operational decentring is one of the major challenges of a philosophy of technoscientific objects today.
} 
reciprocally in the process that Thomas refers to as a "deterritorialization of our interface with the world."

- Charnel character: Touch is usually regarded as the sense of immediacy and sensuality. Instead of exploiting the seductive character of images, the artist chose to show the list of raw data (van der Waals force measures) aside the haptic, visual and sonic renderings of them, without forgetting the algorithms that allow generating them-all things that scientists tend to show less and less. By giving to see and to manipulate the various possible means of transduction of the skin-gold relationship, the project produced a distancing of touch.

- Antitypy ${ }^{22}$ : Rather than a simple means of contact touch reveals to be a topologically singular space, rich of physical and chemical events (forces, particle exchanges, reactions and transitions, e.g. how gold atoms are transferred to the skin). The problem is no longer to render the nanoworld accessible to our familiar sense of space, it is to interpret space anew. In his view, the imaging methods of nanotechnology remain too dependent on visual conventions still belonging to the regime of representation (in particular perspective). He opposes an interstitial and transitional space to the occulocentric and perspectivist understanding of space, a space-between: between humans and objects, between several scales, and between various sensory modalities as well.

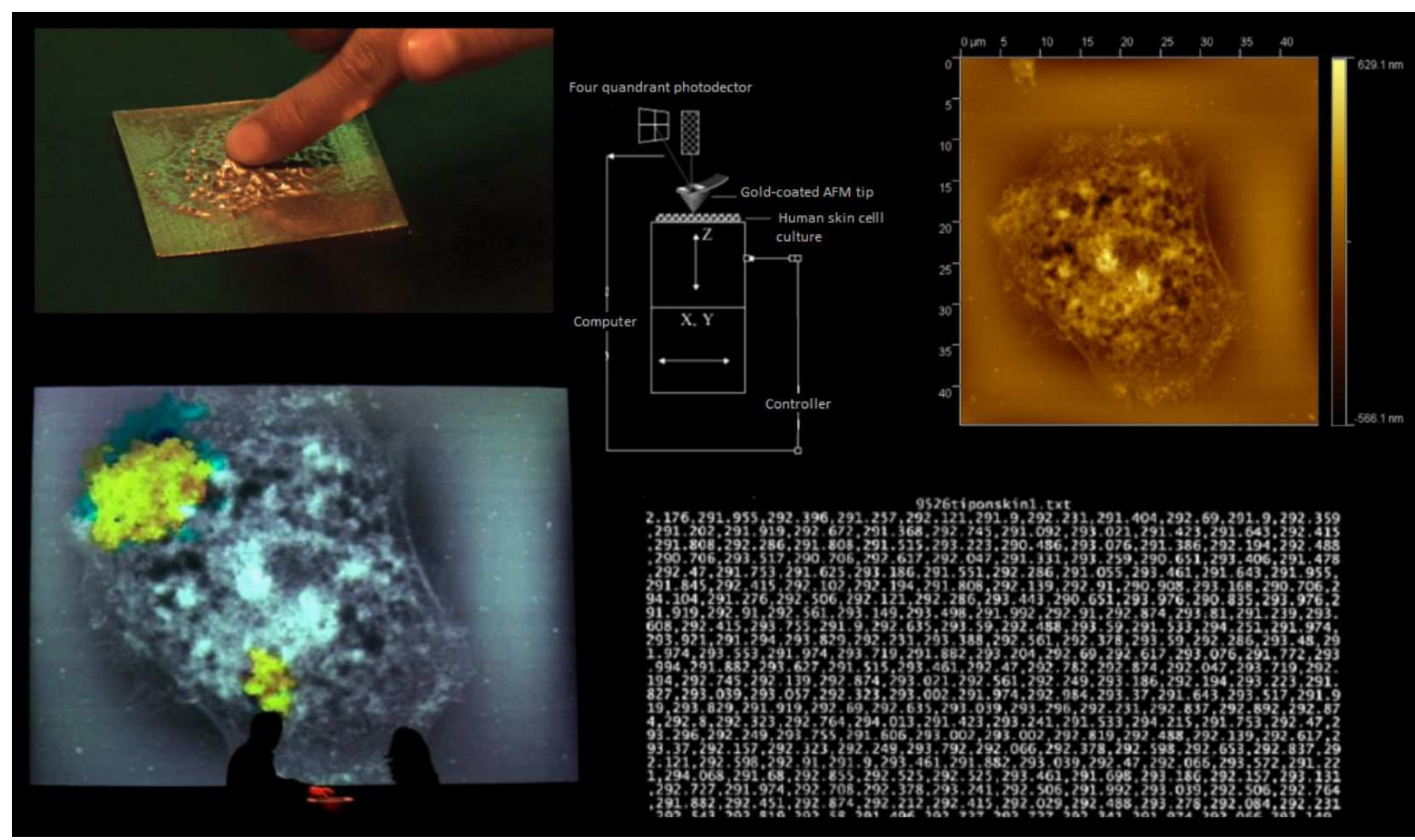

Figure 9. MIDAS project, Paul Thomas. (Courtesy of P. Thomas)

\footnotetext{
${ }^{22}$ Resistance of matter to a penetrative force, by which two objects must occupy two different places.
} 
Loeve, S. (2018). Design and Aesthetics in Nanotechnology. In Loeve, S. Guchet X., \& Bensaude Vincent B. (eds.), French Philosophy of Technology. Classical Readings and Contemporary Approaches, Cham: Springer, pp. 361-384. Post-print version.

2.

In Can you hear the femur play? artist Boo Chapple and biomedical engineering physicist William Wong relate their troubles with engineering "bones audio speakers at the nanoscale." (Chapple and Wong 2008) The project starts from their reading of biology papers on bone piezoelectricity arguing that the bone matrix reacts to mechanical stress by emitting electrical signals captured by the stem cells that regenerate bone tissues. In order to make bone piezoelectricity audible Chapple tries to craft an electro-acoustic transducer out of bones bought from the butcher (Fig. 10).

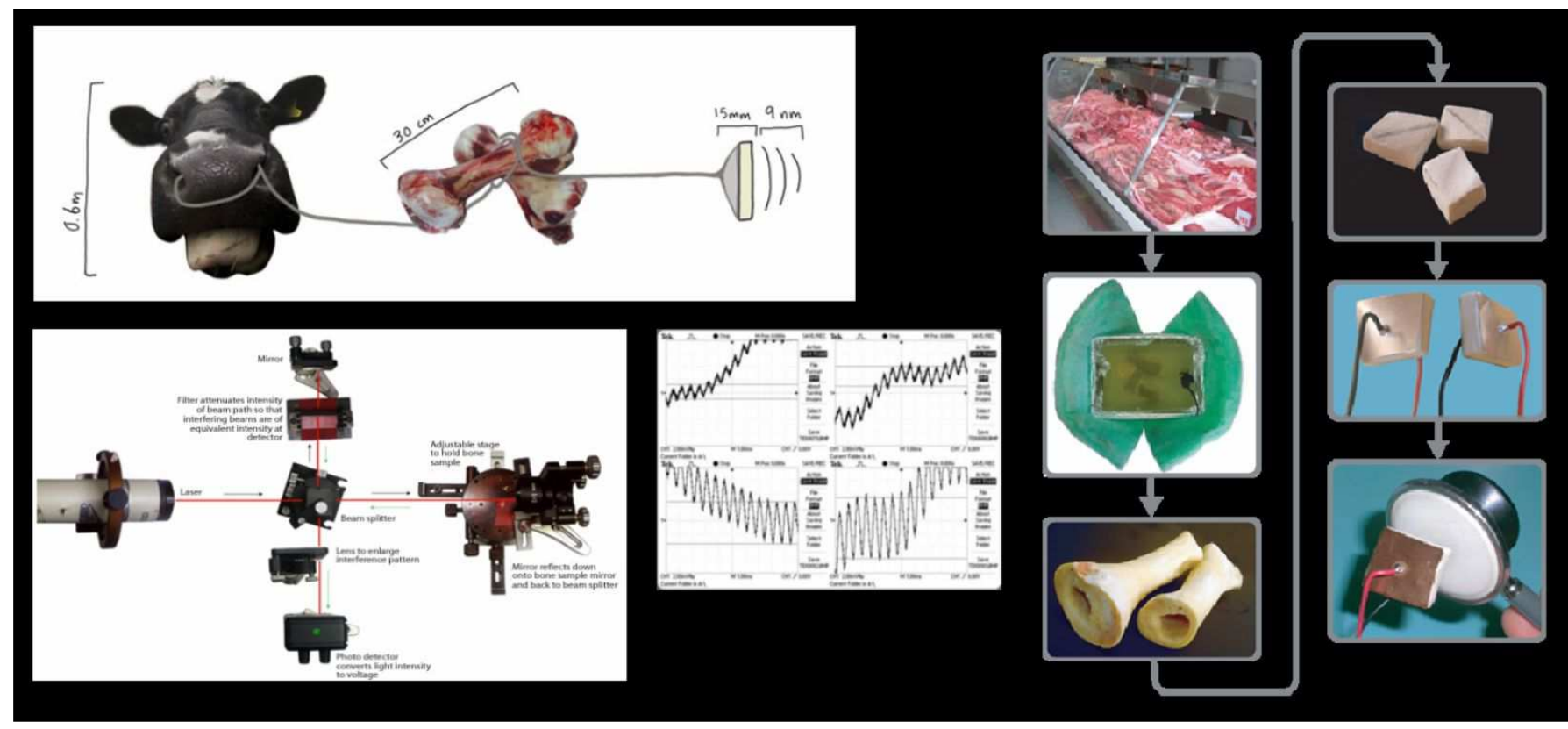

Figure 10. Bone transducers, Boo Chapple and William Wong. (Courtesy of Boo Chapple)

The project lasted for 3 years, with considerable technical hitches. Connected to an electrical circuit, the transducers alone did not work, so they tried using various microphones and oscilloscopes to detect and amplify the sound. Each time they thought getting something they realized it comes from interferences with background noise. At some point, they even built a Michelson interferometer, a sophisticated instrument insensible to electromagnetic perturbations. The apparatus detects a range of frequencies between 300 and $3000 \mathrm{~Hz}$. Given the frequency range of the human ear (from 20 to $20,000 \mathrm{~Hz}$ ), the piezoelectricity should have been audible, but it was not. Doubts aroused about the reality of the phenomenon, about the scientific literature, about trust in science, and about the artist's obsession to "possess" the phenomenon in a "macrosensorial" way. They had "the map, but not the territory," Chapple says. These deceptive results push them to question the role of technology: they had thought getting a tool to accomplish the prowess of "macrosensoriality." Instead of that, the functioning of the device revealed the incommensurability of the forces to which it connects the human operator. They finally managed to amplify the sound of the electrified bones with a simple physician's stethoscope, ending up with a hybrid setup of high- and low-tech, of physicist's and physician's apparatuses.

As the project diverts a biological process from its natural function and turns it into a technical device, Chapple and Wang explicitly raise the issue of the instrumentalization of life: what does it mean to impose technical norms on life? 
But while this issue is usually mixed to that of the commoditization of life, here it is addressed for itself (Guchet 2014: 309), as "technicization" rather than "instrumentalization," one could say. Instead of raising this issue from the viewpoint of a defined society (capitalist, utilitarian, predatory, etc.) they build an experiential and narrative apparatus that allows questioning the technicization of life as a practice, as "a means in itself" rather than as a means for something else. The project does not condemn nor promote the instrumentalization of life, it "makes it strange," and exposes this strangeness to different kinds of questioningaesthetical: how does it feels to experiment life through technology? Anthropological: what does it tell about the relationships of human beings to other species? Ontological: what does it tell about the relationships between life and technology?

3.

Pantoffel für Pantoffeltierchen ("Slippers for sleepy animals") by Grit Ruhland, is a few tenth microns sculpture realized in collaboration with researchers at the Max Planck Institute of Dresden. Made of 60 layers of liquid photopolymer that hardens when irradiated with laser at certain wavelength, it has required considerable work of mask modeling and laser beam programming. In the exhibition, one does not see the sculpture but the glass slide that is supposed to host it; above it, an electron microscope image represents the invisible object (Fig. 11).

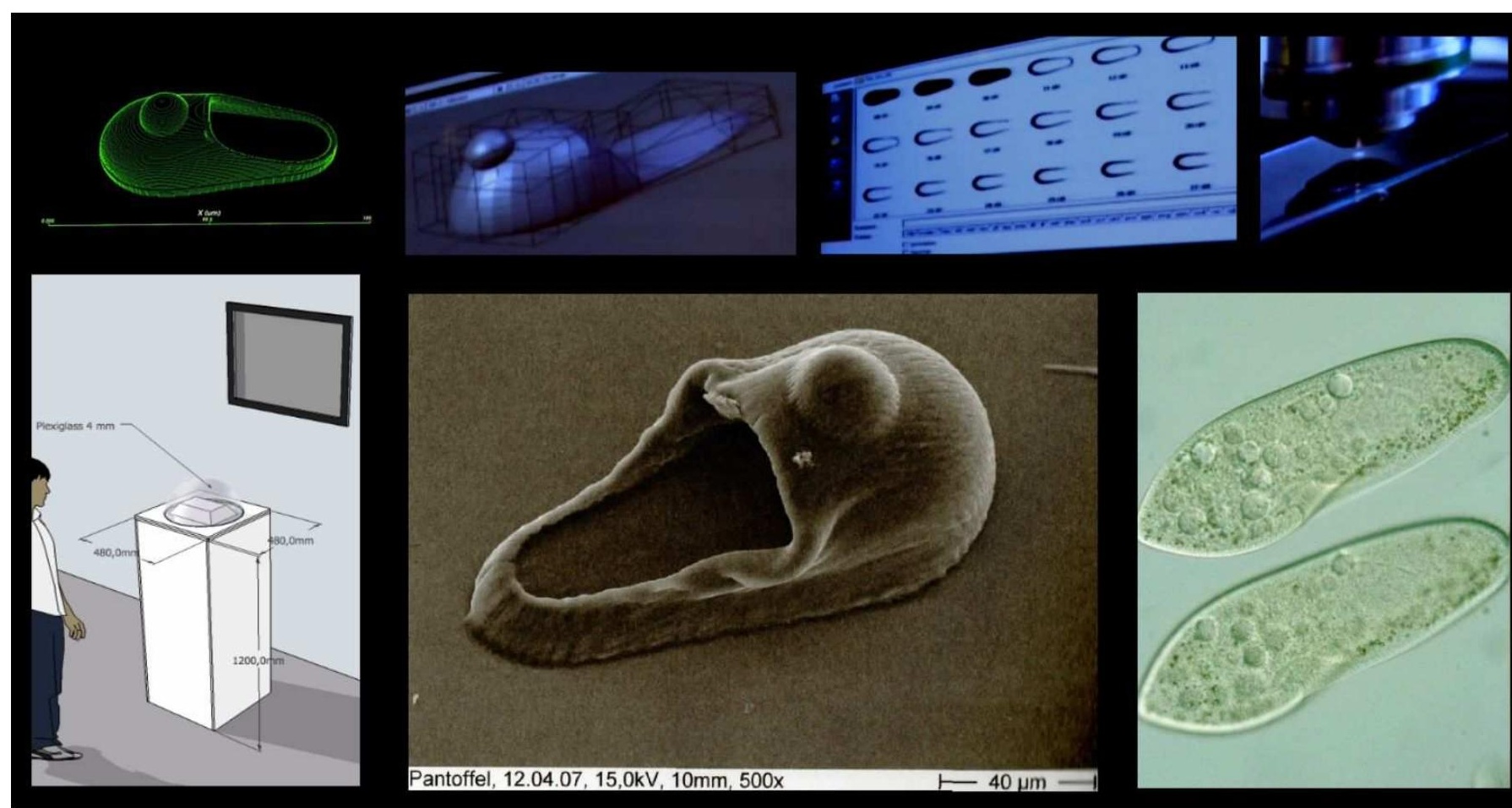

Figure 11. Slippers for sleepy animals, Grit Ruhland. (Courtesy of G. Ruhland)

At first sight, the view of the slipper provokes a feeling of identification and familiarity. It is an everyday-life object, which we habitually use to feel comfort and warm. But when we learn that only a unicellular organism named Paramecium has the good shape and size to fit in the slipper, the feeling of appropriation is impeded. The use-meaning of the object vanishes before reconstituting itself anew, but not for us, humans: for the bacteria in question, thanks to a linguistic circumstance, as it occurs indeed that in German, the vulgar 
name of Paramecia is Pantoffeltierchen, "animals-slippers." The sculpture, dedicated to Paramecia, plays with the meanings conferred by use and by naming: the defeated human use-meaning finally re-weaves itself for non-humans (Paramecia) by the mediation of humans who named this bacteria "animals-slippers" because of the foot-shape of its unicellular body. It is thus stimulating exercise of "disanthropocentrism" that, paradoxically, includes the human.

The three art/technology-works described provide interesting cues to rethink the role of design in nanotechnology in that they do not separate the technical and the aesthetic and do not reconcile them either. In my view, what they do is rather to experiment the making and unmaking of possible "distributions of the sensible." (Rancière 2004)

\section{Distributions of the Sensible}

Philosopher Jacques Rancière defines the "distribution (or sharing) of the sensible" (partage du sensible) as "the implicit law governing the sensible order that parcels out places and forms of participation in a common world by first establishing the modes of perception within which they are inscribed." (Rancière 2004: 85) The distribution of the sensible shapes aesthetics "understood in a Kantian sense-reexamined perhaps by Foucault-as the system of a priori forms determining what presents itself to sense experience." (2004: 12) By producing "a system of selfevident facts of perception based on horizons and modalities of what is visible and audible as well as what can be said, thought, or done," (2004: 85) the concept refers to the recognition of a shared and common world of perception and, simultaneously, the delimitations defining the respective parts and positions of social actors. "This apportionment of parts and positions is based on a distribution of spaces, times, and forms of activity that determines the very manner in which something in common lends itself to participation and in what way various individuals have a part in this distribution." (2004: 12) Therefore the distribution of the sensible introduces politics at the core of aesthetics, "a delimitation of spaces and times, of the visible and the invisible, of speech and noise, that simultaneously determines the place and the stakes of politics as a form of experience." Politics, Rancière writes, "revolves around what is seen and what can be said about it, around who has the ability to see and the talent to speak, around the properties of spaces and the possibilities of time." (2004: 13)

It is possible to give a technological twist to Rancière's political view of aesthetics. The concept of "aesthetical apparatuses," prompted by philosophers of art Jean-Louis Déotte and Pierre-Damien Huyghe is a good candidate (Déotte 2005, 2007; Huyghe 2006, 2012). It refers to all devices that shape, reconfigure and destabilize common sensibility. Not only do Déotte and Huyghe agree with Bernard Stiegler's major thesis of the technologically constituted character of transcendental imagination-what Kant called "schematism," the way by which concepts are translated into sensible images and reciprocally (Stiegler, Chap. 18, this volume)-but they provide documented historical analyses of these reconfigurations, that they reintegrate into the history of art. From pencil to cinematograph to digital imaging, aesthetical apparatuses sketch a history of human sensibility which, far from being harmonious, progressive or linear, is rather intrinsically subject to conflict-conflicts between different ways of feeling, different world-apparatus ensembles, as much as between our imaginative and our technical apparatuses always working in a close but tensed interplay (Hui 2015). In other words there is no a priori logic of the sensible determined by the inner 
structure of the human subject nor is aesthetics a posteriori, determined by the technological environment. The logic of the sensible is constituted a praesenti in our collective interplay and struggles with and within our technical milieu.

For instance, if human access to nanoscale processes depends on choices of transmodality, who is going to chose which perceptive modality allows users access to them and on what grounds? If users' experiences of nano-enabled products depend on delimitations between what is visible and invisible, tangible or intangible, sayable and unsayable, audible and inaudible, who-artists, citizens, designers, engineers, scientists, philosophers, social scientists, industrialists, users, etc.-is granted the legitimacy to determine which features should be rendered sensible? The distribution of social roles of the nanoworld is contingent on techno-aesthetic partitions framing the relationships between the sensible and the sayable, and these partitions should be a matter of public and pluralistic deliberation.

Thus, rather than an ontological given, the division of labor between nanoengineering and design could be understood as a particular distribution of the sensible. By taking up this concept, designers could engage more actively in the design of our interactions with the nanoworld and reflect on its political dimension.

\section{Reconsidering Design As Techno-aesthetics}

The status of design in nanotechnology is paradoxical. In many laboratories around the world, thousands of researchers are designing new experiences enabled by nanotechnology: listening to materials, touching sounds, writing with atoms, communicating with molecules, etc. By contrast in our everyday world, nanoembarking applications are not especially exciting or futuristic; they are unimaginative and poor in design. Most of them invite users to behave as passive consumers of active functions. ${ }^{23}$

Instead of engaging with the nanoworld, designers work only on the symbolic, metaphoric and societal dimensions of future applications and potential uses of nanotechnology, disconnected from its present mode of existence, whose material and operative dimensions are kept out of reach of designers, let to scientists. The intervention of design remains external to the design of the nanoworld. As a result, users are connected to the nano-dimension only by the halo of promises and fears symbolizing "the future."

My proposition is that design should reconsider and perhaps reclaim its role as techno-aesthetics. As I have argued, there is nothing ontologically inaccessible in nano-objects and processes once we look at them through a techno-aesthetic prism. The partition of design between scientists designing an allegedly "invisible" or "noumenal" technology and designers working on its appropriation into everyday life is contingent on distributions of the sensible. The partitions between the interobjective relationships that are rendered sensible and those that are not, between the aesthetics of functioning and the aesthetics of use, or between those who manipulate transmodality and those who are provided with readymade perceptual access, should not be considered as given but as partitions for designers to play with.

Because there is no natural matching between functioning and use, design is always based on techno-aesthetic choices or "organizations of technophany," as Simondon had it (1960-1961: 39). In the case of nano-enabled use experiences, design choices go beyond the technical object, and extend to the way we may or

\footnotetext{
${ }^{23}$ For a large consumer products inventory, see the project on Emerging Nanotechnologies at the Woodrow Wilson Center: http://www.nanotechproject.org/cpi/
} 
may not perceive that with which the object connects us: other living subjects, scales, objects, milieus. Design in nanotechnology is thus crucially concerned with the question of determining what should be rendered sensible as a political issue in our natural and artificial environment (including toxicological issues, environmental impacts, etc.).

Techno-aesthetics can be defined as the study and design of apparatuses that transform the functioning of the sensible. As a field of study, it would be an alliance between "techno-logy" understood as the study of technics-another French tradition (Sigaut 1985) - and aesthetics understood as the study of sensation and feeling. ${ }^{24}$ As a design practice, it would afford intellectual, practical and emotional grasps on nano-enabled experiences. A "good" techno-aesthetic design would not be merely an "engineered" or "technical" aesthetics: It would have to be a "techno-logical" aesthetics or, if the neologism were not too pedantic, an "aesthechnology," a technicity exploratory of itself. In other terms, technoaesthetics would have to be reflexive in order to be politically relevant and to question the technically enabled distributions of the sensible instead of merely imposing them. Rather than "making the insensible sensible" like mainstream nanoart claims to do, designers would have to ask what should be rendered sensible and why, to make intelligible the ways in which the sensible is technically operated and partitioned, and to render these partitions problematic, debatable, and perhaps reversible.

The design of nanotechnology is still to be invented.

\section{Acknowledgements}

A preliminary version of this text has been discussed by Victor Petit and Xavier Guchet during the authors' workshop held in Paris Sorbonne on 22-23 June 2015 for the preparation of the collective book. I want to thank them as well as Anne Guénand and Charles Lenay for their useful comments.

\section{References}

Annaluru, N., Muller, H., Mitchell, L. A., Cai, Y., et al. (2014). Total synthesis of a functional designer eukaryotic chromosome. Science, 344(6179), 55-58.

Antonello, P. (2009). Beyond futurism: Bruno Munari's useless machines. Avant Garde Critical Studies, 24(1), 315-336.

Ashby, M. F., Ferreira, P. J., \& Schodek, D. L. (2009). Nanomaterials, nanotechnologies and design. An introduction for engineers and architects. Burlington: Elsevier.

Audétat, M., Barazzetti, G., Dorthe, G., Joseph, C., Kaufmann, A., \& Vinck, D. (Eds.). (2015). Sciences et technologies émergentes:pourquoi tant de promesses? Paris: Hermann.

Auger, J. (2013). Speculative design: Crafting the speculation. Digital Creativity, 24(1), 11-35.

Baccile, N., \& Balzerani, M. (2013). Invisible and intangible, when art meets nanoscience. Plastik: Art \& Science, 3. ISSN 2101-0323.

Bachelard, G. (1938). La formation de l'esprit scientifique: contribution à une psychanalyse de la connaissance objective. Paris: Vrin.

Bensaude Vincent, B. (2001). A genealogy of the increasing gap between science and the public. Public Understanding of Science, 10(1), 99-113.

\footnotetext{
${ }^{24}$ For an elaboration of techno-aesthetics based on Baumgarten, Bergson, Simondon and Deleuze see Loeve (2011).
} 
Loeve, S. (2018). Design and Aesthetics in Nanotechnology. In Loeve, S. Guchet X., \& Bensaude Vincent B. (eds.), French Philosophy of Technology. Classical Readings and Contemporary Approaches, Cham: Springer, pp. 361-384. Post-print version.

Bensaude Vincent, B. (2015). Life by design: Philosophical perspectives on synthetic biology. In $B I O$ web of conferences (4, p. 00015). EDP Sciences.

Bensaude Vincent, B., Loeve, S., Nordmann, A., \& Schwarz, A. (2011). Matters of interest: the objects of research in science and technoscience. Journal for General Philosophy of Science, $42(2), 365-383$.

Bensaude Vincent, B., Loeve, S., Nordmann, A., \& Schwarz, A. (2017). Research objects in their technological setting. Abington: Routledge.

Bergson, H. (1896). Matière et mémoire. Paris: Alcan. English edition: Bergson, H. (1911). Matter and Memory (trans: Paul, N. M. \& Palmer, W. S.). London: Swan Sonnenschein \& Co.

Bogost, I. (2012). Alien phenomenology, or, what it's like to be a thing. Minneapolis: University of Minnesota Press.

Browne, W. R., \& Feringa, B. L. (2006). Making molecular machines work. Nature Nanotechnology, 1(1), 25-35.

Buchanan, R. (1992). Wicked problems in design thinking. Design Issues, 8(2), 5-21.

Bueno, O. (2008). Visual evidence at the nanoscale. Spontaneous Generations, 2(1), 132-133.

Chapple, B., \& Wong, W. (2008). Can you hear the femur play? Bone audio speakers at the nanoscale. Leonardo, 41(4), 355-359.

Chong, K. P., \& Garboczi, E. J. (2002). Smart and designer structural material systems. Progress in Structural Engineering and Materials, 4(4), 417-430.

Delhome, T. (2011). Innovation et interfaces: de l'intelligence ambiante à l'intelligence sensorielle. In A. Sauvageot, X. Bouju, \& X. Marie (Eds.), Images \& mirages @ nanosciences (pp. 247-256). Paris: Hermann.

Déotte, J.-L. (2005). Appareils et formes de la sensibilité. Paris: L'Harmattan.

Déotte, J.-L. (2007). Qu'est-ce qu'un appareil? Walter Benjamin, Jean-François Lyotard, Rancière. Paris: L'Harmattan.

Dilnot, C. (1984). The state of design history. Part II: Problems and possibilities. Design Issues, 1(2), 3-20.

Drexler, E. K. (1992). New technologies for a sustainable world. Hearing in front of the U.S. Senate Committee on Commerce, Science, and Transportation's Subcommittee on Science, Technology, and Space, June 26, 1992. Foresight Update, 14.http://www.islandone.org/Foresight/Updates/Update14/Update14.1.html\#anchor634804 , Accessed 25 March 2018

Dunne, A. (2006). Hertzian Tales: Electronic products, aesthetic experience, and critical design. Boston: MIT Press.

Foucault, M. (1966). The order of things. An archaeology of the human sciences (English trans: 2002). London: Routledge.

Guchet, X. (2014). Philosophie des nanotechnologies. Paris: Hermann.

Hanson, V. L. (2012). Amidst nanotechnology's molecular landscapes: The changing trope of subvisible worlds. Science Communication, 34(1), 57-83.

Harman, G. (2011). The quadruple object. Winchester/Washington, DC: Zero Books.

Hawkins, H., \& Straughan, E. R. (2014). Nano-art, dynamic matter and the sight/sound of touch. Geoforum, 51, 130-139.

Hui, Y. (2015). Induction, deduction and transduction: On the aesthetics and logic of digital objects. Networking Knowledge, 8(3), 1-19.

Huyghe, P. D. (2006). L'art au temps des appareils. Paris: L'Harmattan. 
Loeve, S. (2018). Design and Aesthetics in Nanotechnology. In Loeve, S. Guchet X., \& Bensaude Vincent B. (eds.), French Philosophy of Technology. Classical Readings and Contemporary Approaches, Cham: Springer, pp. 361-384. Post-print version.

Huyghe, P. D. (2012). Le cinéma avant après. Grenoble: De l'incidence éditeur.

Jones, R. A. L. (2004). Soft machines. Nanotechnology and life. New York: Oxford University Press.

Lévy-Leblond, J.-M. (2010). La science (n’) e(s)t (pas) l'art. Brèves rencontres. Paris: Hermann.

Loeve, S. (2009). Le concept de technologie à l'échelle des molécules-machines. Philosophie des techniques à l'usage des citoyens du nanomonde. $\mathrm{PhD}$ thesis, University Paris Ouest.

Loeve, S. (2010). About a definition of nano: How to articulate nano and technology. HYLEInternational Journal for Philosophy of Chemistry, 16(1), 3-18.

Loeve, S. (2011). Sensible atoms: A techno-aesthetic approach to representation. NanoEthics, 5(2), 203-222.

Loeve, S. (2015). La notion d'objet relationnel dans les nanotechnologies (avec et après Simondon). Cahiers Simondon, 6, 47-109.

Loeve, S. (2016). L'ATP synthase: un moteur moléculaire? (petit récit technique). In V. Bontems (Ed.), Gilbert Simondon ou l'invention du futur (pp. 131-145). Paris: Klincksieck.

Marcovitch, A., \& Shinn, T. (2014). Towards a new dimension. Exploring the nanoscale. New York: Oxford University Press.

Meillassoux, Q. (2010). After finitude: An essay on the necessity of contingency. London: Bloomsbury Publishing.

Milburn, C. (2011). Just for fun: The playful image of nanotechnology. NanoEthics, 5(2), $223-$ 232.

Nordmann, A. (2005). Noumenal technology: Reflections on the incredible tininess of nano. Techné, 8(3), 3-23.

Nordmann, A. (2006). Collapse of distance: Epistemic strategies of science and technoscience. Danish Yearbook of Philosophy, 41, 7-34.

Nordmann, A. (2007). If and then: A critique of speculative nanoethics. NanoEthics, 1(1), 3146.

Ottino, J. M. (2003). Is a picture worth 1,000 words? Exciting new illustration technologies should be used with care. Nature, 421(6922), 474-476.

Raimond, J. M., Brune, M., \& Haroche, S. (2001). Manipulating quantum entanglement with atoms and photons in a cavity. Reviews of Modern Physics, 73(3), 565-582.

Raimondi, S. (2007). NanoArt. Vedere l'invisibile. Milan: Skira.

Rancière, J. (2004). The politics of aesthetics: The distribution of the sensible. London/New York: Continuum.

Rieth, M. (2003). Nano-engineering in science and technology. An introduction to the world of nano-design. Singapore: World Scientific Publishing.

Roco, M. C., et al. (1999). Nanotechnology: Shaping the world atom by atom. Washington, DC: National Science and Technology Council Committee on Technology, Interagency Working Group on Nanoscience, Engineering and Technology. http://www.wtec.org/loyola/nano/IWGN.Public.Brochure/IWGN.Nanotechnology.Brochure.pdf, Accessed 25 March 2018

Ruivenkamp, M., \& Rip, A. (2010). Visualizing the invisible nanoscale study. Science Studies, 23(1), 3-36.

Schommers, W. (2013). Nanodesign: Some basic questions. Singapore: World Scientific Publishing. 
Schummer, J. (2006). Gestalt switch in molecular image perception: The aesthetic origin of molecular nanotechnology in supramolecular chemistry. Foundations of Chemistry, 8(1), 5372 .

Shwartz, M. (2015). Designer carbon could give batteries a makeover. http://www.futurity.org/designer-carbon-batteries-932482/ . Accessed 18 June 2015.

Sigaut, F. (1985). More (and enough) on technology! History and Technology, an International Journal, 2(2), 115-132.

Simondon, G. (1958). Du mode d'existence des objets techniques (2nd ed. 1989). Paris: Aubier. English edition: Simondon, G. (2017). On the Mode of Existence of Technical Objects (trans: Malaspina, C.). Minneapolis: Univocal Publishing.

Simondon, G. (1960-1961). Psychosociologie de la technicité. In G. Simondon (2014), Sur la technique (pp. 27-129). Paris: Presses Universitaires de France.

Simondon, G. (2005). L'individuation à la lumière des notions de forme et d'information. Paris: Millon.

Simondon, G. (2008). Imagination et invention. Paris: L'Éclat.

Slaattelid, R. T., \& Wickson, F. (2011). Imag(in)ing the nano-scale: Introduction. NanoEthics, 5(2), 159-163.

Snow, C. P. (1959). The two cultures and the scientific revolution: The Rede Lecture. Cambridge: Cambridge University Press.

Stroscio, J. A., \& Celotta, R. J. (2004). Controlling the dynamics of a single atom in lateral atom manipulation. Science, 306(5694), 242-247.

Thomas, P. (2009). Midas: A nanotechnological exploration of touch. Leonardo, 42(3), 186192.

Toumey, C. (2010). 35 atoms that changed the nanoworld. Nature Nanotechnology, 54(4), 239-241. 